\title{
Exploring the Interpersonal Dimension of Teaching in an Irish Post- Primary Context
}

Darina Scully*, Vasiliki Pitsia and Anastasios Karakolidis

Centre for Assessment Research, Policy and Practice in Education, Institute of Education (CARPE), Dublin City University, Ireland

*Corresponding author. Email: darina.scully@dcu.ie.

CARPE Twitter: @carpe_dcu 


\section{Exploring the Interpersonal Dimension of Teaching in an Irish Post- Primary Context}

Word Count: 6,810

Effective teaching encompasses both a pedagogical and an interpersonal dimension. Despite this, the latter typically receives little attention in initial teacher education and professional development programmes because of its tacit, non-conscious, and context-specific nature. In this study, the interpersonal dimension of teaching was conceptualised in terms of an explicit set of problemsolving strategies. Using the Tacit Knowledge Inventory for High School Teachers (TKI-HS), the perceived effectiveness of these strategies amongst a sample of Irish post-primary teachers $(n=69)$ was explored, and the extent to which this varied across certain individual and contextual factors was also investigated. The findings suggest that, when faced with challenging social situations in the course of their professions, Irish post-primary teachers demonstrate preferences for strategies involving either rational discussions with the source of the problem, or appealing to a colleague for advice. These preferences were independent of the teachers' gender, education level, degree of job satisfaction, and the climate of the school in which they worked. Some implications for teacher education programmes are outlined. Potential future directions, including links to broader issues concerning the assessment of noncognitive skills and competencies more generally, are also discussed.

Keywords: teaching, post-primary, interpersonal skills, problem-solving, tacit knowledge

\section{Introduction}

\section{Teacher Effectiveness}

A wealth of educational research literature points towards the wide-reaching impact of teacher effectiveness. Indeed, findings from large-scale international studies have consistently revealed that among various school-level factors, teacher quality has the greatest impact on student achievement (e.g. OECD, 2005; Guerriero, 2017), and teacher excellence has been identified as the single most important element of high- 
performing education systems such as those of Finland (Sahlberg, 2010) and Singapore (Steiner, 2010). Thus, improving teacher effectiveness is clearly a worthwhile goal for education systems worldwide. As Looney (2011) outlined, although there is no agreedupon definition of teacher quality, research has identified a number of characteristics exhibited by the most effective teachers. These include: (i) general cognitive ability, (ii) good content knowledge, (iii) pedagogical content knowledge (including assessment literacy), (iv) strong classroom management skills, and (v) the ability to develop positive relationships and work collaboratively with others. The latter of this list might well be described as the 'interpersonal' dimension of teaching.

\section{The Interpersonal Dimension of Teaching}

Jones, Bouffard and Weissbourg (2013) attempted to unpack the interpersonal dimension of teaching, highlighting social processes such as understanding social cues and correctly attributing the intent of others' behaviours and emotional processes such as regulating one's own emotions and behaviours and taking others' perspectives into account. Their assertion - that these competencies 'are not secondary to the mission of education, but are concrete factors in the success of teachers' (Jones et al., 2013, p. 62) - echoes the sentiments of others and has been well supported in international research literature. For instance, in a survey of school principals (Torff \& Sessions, 2005), lack of ability to establish a rapport with students was among the most frequently perceived causes of teacher ineffectiveness. Teachers' interpersonal skills have also been identified as important in establishing relationships with colleagues and parents (Stemler, Elliot, Grigorenko and Sternberg, 2006). Moreover, teachers with good emotional regulation skills have higher job satisfaction and increased feelings of personal accomplishment (Brackett, Palomera, Mojsa, Reyes and Salovey, 2010). 
Despite the well-recognised importance of the interpersonal dimension of teaching, international research suggests that it is seldom a prominent feature of initial teacher education (ITE) programmes or continuous professional development (CPD) programmes, both of which tend to focus on skills in instructional practice (Patti et al., 2015; Zeichner, 2012). Instructional skills undoubtedly form a significant element of what it means to be a good teacher. However, as Zeichner (2012, p.379) pointed out, an exclusive focus on teaching practices risks 'narrowing the role of teachers to that of technicians who are able to implement a particular set of teaching strategies, but who do not develop... the relational skills they need to be successful in the complex institutional settings in which they will work.'

The relative lack of emphasis placed on the interpersonal dimension of teaching in formal education is perhaps attributable to the fact that it depends heavily on knowledge that is procedural rather than declarative. Procedural knowledge is knowledge applied to a particular task, i.e., it involves knowing how as opposed to knowing that. Due to its tacit or non-conscious nature, it is 'usually not openly expressed or taught' (Wagner \& Sternberg, 1985, p.436); indeed, the interpersonal dimension of teaching is typically assumed to result from experience and general socialization rather than from direct instruction (Stemler et al., 2006). However, given the strong evidence supporting the interpersonal dimension of teaching, it may be time to give greater consideration to understanding this constellation of skills, and whether it can be developed in both pre-service and practising teachers.

\section{The Irish Context}

As this study focuses on the post-primary education system in the Republic of Ireland, it is important to consider the above issues specifically in relation to this 
context. As Stemler et al. (2006, p.102) pointed out, the need for teachers to have welldeveloped skills in dealing with social situations is heightened in cultures wherein 'student independence and autonomy are particularly prized' and wherein educational practice is subject to considerable scrutiny by stakeholders such as parents, administrators and the media. Both of these are at play in the Irish context: an enhanced focus on student autonomy is evident in the framework for the new Junior Cycle at postprimary level (DES, 2015); furthermore, a growing emphasis on accountability and performativity across the entire system continues to place demands on Irish teachers from various external sources (Conway \& Murphy, 2013).

Additionally, it has been argued that a growing emphasis on social and emotional learning in many school curricula may heighten the need for teachers to have advanced interpersonal skills (Patti et al., 2015). This phenomenon is clearly evident in the Irish post-primary context, with wellbeing identified as a core area of learning in the new Junior Cycle programme. Junior Cycle students in Ireland are expected to acquire skills in 'developing good relationships and dealing with conflict', 'co-operating' and 'being social' as part of their schooling (DES, 2015). As argued by Patti et al. (2015), teachers in such contexts must themselves have well-developed skills in these areas such that they may effectively model them for students. These authors used the term 'emotional intelligence', and suggested that this is manifest in teacher behaviours such as 'how they communicate with colleagues and students, how they process feedback from others, and how they manage conflict and stress' (Patti et al., 2015, p.102).

Of particular note is that Irish teachers themselves regard interpersonal skills as an important aspect of their profession. Indeed, in a survey of primary and post-primary school teachers in Ireland (Devine, Fahie \& McGillicuddy, 2013), the statements 'is compassionate and sympathetic', 'establishes and maintains good parent/teacher 
relationships' and 'is a good team player on the staff' were rated as being 'important' or 'highly important' characteristics of a good teacher by $92.9 \%, 84.6 \%$ and $84.2 \%$ of respondents respectively. Devine et al. (2013) acknowledged that there was a tendency for respondents to rate all of the items on this questionnaire more rather than less positively; nonetheless, these findings suggest that the interpersonal dimension of teaching is regarded as being at least as important as others (e.g. the ability to effectively plan and manage learning) in determining teacher effectiveness in this country.

In light of the above, it is important to consider whether sufficient emphasis is placed on the interpersonal dimension of teaching in ITE programmes in Ireland, or if it is somewhat overshadowed by a dominant focus on instructional practice, as seems to be the case in other jurisdictions. The Teaching Council of Ireland (2017) have outlined a series of overarching aims and specific learning outcomes for ITE programmes in this country. Amongst the aims are some references to the interpersonal dimension of teaching (e.g. 'programmes should prepare teachers... to engage with colleagues, coprofessionals and parents'). Similarly, some of the learning outcomes also encompass key aspects of the phenomenon (e.g. 'the graduate will be able to foster good relationships with and among pupils based on mutual respect and trust and meaningful interactions'). It is stated that evidence of these learning outcomes should be accrued from a combination of factors, including ongoing assessment of coursework and observation during school placements. The latter, in particular, would seem to present a suitable opportunity for pre-service teachers (PSTs) to develop and receive feedback on their skills in the interpersonal dimension.

Individual programme syllabi provide an additional source of information about the relative weight placed on the interpersonal dimension of teaching in ITE. For 
example, in an overview of the Professional Masters in Education (PME) offered by Trinity College, Dublin (TCD) the course is said to prepare new entrants for the teaching profession 'who are knowledgeable and reflective about the aims and processes of education and are subject experts in their chosen discipline' (TCD, 2017, p.33). It further states the intention to develop practitioners who are "professional in all aspects of their work', which arguably could include the interpersonal dimension of teaching. There is, however, no explicit mention of interpersonal skills.

Consultation of policy documents and programme syllabi provides insight into intended learning outcomes, but it should be appreciated that these may not always reflect the lived reality for PSTs. Data relating specifically to post-primary PSTs' experiences are, to the best of our knowledge, not available, however, findings from a recent survey of final year primary PSTs (M O’Leary, 2018, personal communication) are interesting in this regard. Specifically, almost all (>95\%) of these PSTs agreed that their ITE programme had improved their understanding of how children learn, and provided them with some of the skills to be an effective teacher, but only two-thirds agreed that the course had prepared them to 'handle challenging classroom situations'.

As mentioned previously, many people regard the interpersonal dimension of teaching as a tacit entity that is almost trait-like in nature. Following this line of thought, it could be argued that instead of attempting to include interpersonal skill development as part of an ITE programme curriculum, it may be more appropriate to include methods to identify people who are high on this trait, e.g. interviews, as part of the selection process for these programmes. In Ireland, whether or not this occurs varies across different universities and higher education institutions offering ITE programmes for post-primary teachers. Many rely solely on information about prior 
academic achievement derived from central application systems, but some also conduct interviews as an additional screening procedure (Darmody \& Smyth, 2016).

Despite the routine use of interviews as a selection tool in many contexts, it cannot be assumed that they are indeed an appropriate means of identifying those with the requisite interpersonal skills to teach. Indeed, as Klassen and Kim (2019) pointed out, there is a distinct lack of research justifying the use of interviews to select PSTs. Moreover, it may not be entirely accurate to classify the interpersonal dimension of teaching as a decidedly tacit entity that is unlikely to be influenced by formal instruction. Rather, it may be possible to address these skills more explicitly in both ITE and CPD contexts if their nature could be articulated with greater clarity.

\section{A Conceptual Framework: Interpersonal Skills as Problem-Solving}

Stemler et al. (2006) have provided an invaluable conceptual framework to support a greater understanding of the interpersonal dimension of teaching. The framework is rooted in Sternberg's theory of practical intelligence (Sternberg, 1999), which states that intelligence in any given domain comprises analytical, creative and practical skills. Analytical skills are those applied to relatively familiar situations, whilst creative skills are those applied to novel situations. In both cases, the situations are likely to be fairly abstract in nature. Practical skills, on the other hand, apply to real problems confronted in everyday life. Often colloquially described as 'street smarts', practical skills are linked to a particular context and they can be further divided into (i) dealing with self, (ii) dealing with others, and (iii) dealing with tasks.

Stemler et al. (2006) thus conceptualized the interpersonal dimension of teaching as a set of practical skills in dealing with others. Specifically, they posited that there is a finite set of problem-solving strategies in which teachers may engage when 
dealing with challenging situations involving either students, parents or colleagues. Furthermore, they sought to detect and categorise these strategies through a series of interviews with experienced teachers. During these interviews, teachers were asked to describe specific 'critical incidents' that they had actually encountered during their careers, to describe how they had handled these incidents, and finally, to suggest a range of other possible ways in which they might have been handled. A content analysis of the interview responses revealed seven strategies, each of which is defined in terms of the observable behaviours with which it is associated (see Table 1). The content validity of these strategies was supported through discriminant analysis.

\section{Table 1 near here}

\section{Identifying 'Good' and 'Bad' Problem-Solving: Consensus-Based Judgement}

The extent to which each of the above interpersonal problem-solving strategies may be considered to be preferable is not necessarily universal. Unlike situations involving declarative knowledge, it is not the case that one of the above strategies is demonstrably 'good' or 'correct', and another 'bad' or 'incorrect'. This reflects a significant and recurrent challenge faced by those attempting to define and measure complex, non-cognitive skills - and one which has been addressed using several different approaches (see Bergman, Drasgow, Donovan, Henning \& Juraska, 2006). One such approach, the expert judgement method, involves determining the relative 'correctness' or appropriateness of different response options in assessments of complex constructs according to the opinions of bona fide subject matter experts. Depending on the construct in question, however, it can be difficult to identify exactly who these experts should be. 
An alternative to the expert judgement method is the use of consensus-based judgement, whereby the appropriateness of the various options is defined by the response distribution of a pilot sample who are knowledgeable concerning the subject matter, but do not necessarily qualify as experts. Although unpalatable to some, there is compelling evidence for the effectiveness and utility of consensus-based judgement to determine what constitutes a 'correct' or an 'incorrect' response in situations involving tacit and procedural types of knowledge (Legree, Psotka, Tremble \& Bourne, 2005). It follows that it may be possible to identify which of Stemler et al.'s (2006) problemsolving strategies can be considered as 'good' or 'bad' in the Irish post-primary context, and consequently, articulate with some degree of clarity what it means to be skilled in the interpersonal dimension of teaching in this context, by consulting a sample of practising post-primary teachers in Ireland.

Although consensus-based judgement is a helpful tool, it is acknowledged that there are further complications that need to be considered. First, it is entirely possible that the consensus-determined effectiveness of various strategies may depend to some degree on the nature of the situation (Stemler et al., 2006). Second, the level of experience of the teachers in the sample may come into play. Elliott, Stemler, Sternberg, Grigorenko and Hoffman (2011), for example, revealed that PSTs tended to endorse the consult strategy more so than their practising counterparts. In addition, as Eaude (2015, p.16) pointed out, when considering the concept of effectiveness in the teaching profession, it is also important to 'take account of the expectations of teachers resulting from policy at school and national level'. That is, in schools experiencing higher levels of parental involvement, a strategy such as confer may be encouraged when dealing with situations involving parents. At a broader level, certain cultural and societal beliefs regarding child development and education are also likely to have an 
influence. Indeed, differences have been reported in how experienced teachers across different countries rate these interpersonal problem-solving strategies (Authors et al., 2018), thus highlighting the necessity to collect data from a sample of practising teachers in Ireland, rather than relying on consensus judgement from other jurisdictions to inform practice in this country.

\section{Outline of the Study}

With all of the above considerations in mind, this study explores how the interpersonal dimension of teaching plays out in an Irish post-primary context. Guided by Stemler et al.'s (2006) conceptual framework, and by previous studies exploring this framework in a U.S. context (e.g. Elliott et al., 2011), our primary aim is to identify which problem-solving strategies are typically preferred and avoided by a sample of Irish teachers when faced with challenging interpersonal situations associated with their profession, and in doing so, provide a helpful reference point for ITE programme providers seeking to support their students in developing these skills. Acknowledging the potential shortcomings of the consensus-based judgement approach, we also explore the extent to which these preferences are dependent on (i) the nature of the particular situation and (ii) individual and contextual factors such as years of experience and school climate. 


\section{Method}

\section{Measures}

\section{Demographics}

A series of questions were included to gather basic demographic and background information about the teachers participating in this study. These questions pertained to participants' gender, level of education, main subject area, years of experience in the profession, and the number of different schools in which they had taught.

\section{Job Satisfaction and School Climate}

In order to gather further contextual information, two additional questions were included. The first of these was comprised of a series of items from the PISA 2015 General Teacher Questionnaire (OECD, 2014) and was intended to address teachers' overall level of job satisfaction (encompassing their satisfaction with the teaching profession, and, more specifically, with their current job environment). The second was comprised of a series of items from the TIMSS 2015 Teacher Questionnaire and was intended to measure the general climate of the school in which the teacher currently worked (including issues pertaining to student behaviour and the level of parental involvement). Table 2 displays each set of items - note that some have been adapted slightly from their original format to ensure that the same Likert-style response options could be used across all statements (strongly disagree, disagree, agree, strongly agree). Items were reverse-scored where appropriate, and participants' responses were summed to give two separate scales, one pertaining to overall level of job satisfaction and one pertaining to the overall school climate. Both scales had satisfactory levels of internal consistency (Cronbach's Alpha $=.87$ and .91 respectively), and the possible scores on each scale ranged from 8 to 32 . 


\section{Table 2 near here}

\section{The Tacit Knowledge Inventory for High-School Teachers (TKI-HS)}

An adapted version of the TKI-HS (Stemler, Elliott, Grigorenko, Jarvin \& Sternberg, 2002) was used to gather information about teachers' preferred interpersonal problemsolving strategies. Developed using the situations and strategies identified through interviews with experienced teachers, the TKI-HS consists of eleven scenarios describing challenging interpersonal situations that a teacher may encounter, involving either parents, students, administrators or colleagues. After each scenario, respondents are required to rate the extent to which they agree or disagree with each of seven possible options for responding to that scenario, using a seven-point Likert scale. Each response option corresponds to one of the seven interpersonal problem-solving strategies outlined in Stemler et al's (2006) framework. Consent to adapt the TKI-HS for use in an Irish context, and to use the adapted instrument for this study was obtained by the researchers through personal communication with Steven Stemler.

Figure 1 presents an example scenario and its corresponding response options. Note that, in this example, the problem-solving strategies are identified in brackets for clarification, but these were not included when the participants rated the response options.

\section{Figure 1 near here}

It is important to emphasize that the TKI-HS was used as a survey instrument and not a test instrument in this study. That is, the instrument was used with the aim of 
gathering information about how post-primary teachers in Ireland rate various interpersonal problem-solving strategies, with their pooled responses providing a consensus judgement as to the efficacy of these strategies, and thus a collective understanding of what it might mean to be skilled in the interpersonal dimension of teaching in this context. Individual teachers in this study did NOT receive 'scores' pertaining to their own interpersonal skills based on their responses to the TKI-HS, as has been the case in some previous studies using this instrument (e.g. Grigorenko, Sternberg \& Strauss, 2006).

\section{Open-Ended Question}

Teachers were provided with the opportunity to comment further on the scenarios and/or to rationalise their choice of problem-solving strategies by means of an openended question (If you have any further comments, please feel free to share them with $u s)$.

\section{Procedure}

Ethical approval for this study was granted by Dublin City University's Research Ethics Committee in February 2018. Following this, the demographic and contextual questions were compiled together with the TKI-HS and open-ended question to form an online survey, using e-survey creator software, and the survey link was circulated widely amongst post-primary teachers in Ireland. Social media were used to explicitly target members of the Teachers' Union of Ireland (TUI) and the Association of Irish Secondary Teachers (ASTI) - the two major post-primary teaching unions in the Republic of Ireland - and the link was also sent directly to personal and professional contacts of the researchers. Participation in the study was voluntary and confidential and each participant gave their informed consent prior to their participation. To ensure 
anonymity, the option to save IP addresses of the participants was disabled in the creation of the survey. 


\section{Findings and Discussion}

\section{Respondent Profile}

Eighty-one post-primary teachers completed or partially completed the online survey, however, some of these withdrew at an early stage. For the analysis, only those who had completed the demographic questions, contextual questions and at least one of the TKI$H S$ items $(n=69)^{1}$ were retained. Table 3 displays the characteristics of the final sample. Respondents were predominantly female (71\%), and held either a Bachelor's or Master's degree (94.2\%). Level of experience ranged from less than one year to more than thirty years, and teachers from all major subject areas were represented. Almost $40 \%$ of the sample indicated that they had worked in more than four different schools throughout their career.

\section{Table 3 near here}

Generally speaking, the teachers surveyed seemed satisfied with their choice of career (see Table 4). The lowest level of job satisfaction recorded was 17, whilst many $(n=8)$ respondents achieved the maximum score of 32 on this scale. Indeed, over $90 \%$ of the teachers surveyed agreed that 'the advantages of being a teacher clearly outweigh the disadvantages', while just $8.6 \%$ indicated that they regretted becoming a teacher. When compared to OECD averages (see Mostafa \& Pal, 2018), these responses indicate relatively high levels of satisfaction. Scores on the school climate scale were also quite high, indicating that the majority of teachers worked in positive school climates,

\footnotetext{
${ }^{1}$ Fifty of these 69 respondents completed all of the TKI-HS items
} 
characterized by relatively high levels of parental involvement, and relatively low levels of disciplinary challenges.

Table 4 near here

\section{Teachers' preferred problem-solving strategies}

Figure 2 provides the mean ratings given by the teachers to each of seven problemsolving strategies across all eleven scenarios depicted in the TKI-HS. It is clear that the confer strategy (whereby the teacher makes an attempt to engage in a rational discussion with the 'source' of a problem) and the consult strategy, (whereby a teacher appeals to a third party for advice on how to solve a problem) were generally preferred, with mean ratings of 5.32 and 5.05 respectively. The delegate strategy, (whereby a teacher absolves him/herself of responsibility for action), on the other hand, was least popular, receiving a mean rating of 2.99 across all scenarios.

\section{Figure 2 near here}

\section{Preferred strategies by situation}

Although the above statistics provide an overview of how each strategy fared, they do not take into account the fact that different strategies may be more or less appropriate in different situations. With this in mind, Table 5 provides a more detailed overview of teachers' preferences, specific to each scenario. It is clear from this table that some strategies were rated relatively consistently across all scenarios. The mean rating for the confer strategy, for example, never fell below the neutral point (4) on the scale; conversely, the mean rating for the delegate strategy only surpassed the neutral point on one occasion. 
Another way of thinking about these data is to consider the 'best' and 'worst' responses to each scenario (i.e. those receiving the highest or lowest mean ratings as indicated in Table 5). Unsurprisingly, in multiple situations, either the confer or the consult strategy was deemed to be the 'best response'. The picture is less clear-cut, however, when considering the 'worst' responses. Indeed, four different strategies comply, retaliate, avoid and delegate - emerged as the 'worst' response on more than one occasion.

\section{Table 5 near here}

Returning to individual strategies, comply makes for a particularly interesting case, with mean ratings for this strategy ranging from a low of 1.19 (and categorized as the 'worst' response) in Scenario 1, to a high of 6.25 (and categorized as the 'best response) in Scenario 5. Given that this strategy is defined as 'taking an action that can be interpreted as actively condoning the behaviours of others', it makes sense that its suitability may depend heavily on the nature of the situation. In Scenario 1, for example, the comply strategy involved accepting a student's invitation to go out for a coffee after school hours, whilst in Scenario 5, the comply strategy involved a teacher agreeing to give more challenging assignments to a bright student who has become increasingly disruptive in class (see Appendix for more details of these scenarios). Although both of these actions could be interpreted as condoning the student's original behaviour, the latter could be viewed as a positive step in attempting to reduce the undesirable behaviour, whilst the former is universally understood to be highly inappropriate in the context of a teacher-student relationship.

The perceived appropriateness of the consult strategy also tended to fluctuate somewhat, with relatively high mean ratings for this strategy in eight of the given 
scenarios, but low to neutral ratings in three others. As mentioned previously, this strategy involves appealing to others for advice on how to solve a problem. One possibility is that consultation may be viewed as an indication of incompetence in situations where there are certain protocols that teachers are expected to be aware of, such as that depicted in Scenario 1. However, as one teacher commented in the openended section, 'advice from others should never be seen as weak... all teachers should be encouraged to confide and seek assistance.' The question of whom or what is to be consulted may also be an important factor. Interestingly, in the vast majority of scenarios in the TKI-HS, the suggested consultation tended to be with a professional 'other', such as a teaching colleague, the principal, the Board of Management, or the school's official policy regarding a particular matter. However, in the case of Scenario 10, in which the consult strategy emerged as the 'worst' option, it involved the teacher's family (see Appendix for more details of this scenario). Thus, it seems that consultation is more likely to be viewed as an effective strategy if the person to be consulted is knowledgeable and experienced in the school context.

\section{Individual/contextual factors and choice of problem-solving strategy}

Additional analyses were conducted to investigate the extent to which preferences for particular strategies were associated with individual and/or contextual factors. Interestingly, strategy ratings did not differ according to teachers' gender, level of education or years of experience in the profession (all $p \mathrm{~s}>.05$ ) suggesting there is a certain degree of uniformity in how these strategies are viewed by various teachers in Ireland. It is perhaps surprising that the number of years in teaching did not yield different strategy choices, particularly as interpersonal skills are thought to be developed through experience (Stemler et al., 2006). However, the majority (80\%) of 
teachers in this sample had more than five years of experience, and it has been argued that the greatest degree of development and adaptation occurs in the first five years of the teaching profession (Darling-Hammond, 2000) with many performance indicators tending to level off after this time. Interestingly, previous research using the TKI-HS with a sample of American high-school teachers (Elliott et al., 2011) also failed to find differences between the strategy preferences of more and less experienced teachers, however, as noted previously, significant differences did emerge when PSTs' ratings were compared to those of practising teachers. As no PSTs were included in the current study, no inferences can be made about this issue in the Irish context at this point.

This study extended the scope of Elliott et al. (2011)'s work by considering the role of additional factors such as job satisfaction and school climate in determining teachers' strategy preferences. A small negative correlation was observed between teachers' levels of job satisfaction and their ratings of the retaliate strategy $(r=-.29, p<$ $.05)$. Taken at face value, this suggests that those who are less content in their teaching role may be more likely to favour this somewhat impulsive and poorly-rated strategy. However, as this observation is based on just one significant association emerging from a large correlation matrix, it should be interpreted with caution. Indeed, a Bonferroni correction would render this finding non-significant $(p>.004)$. On the whole, it can be concluded that teachers' ratings of problem-solving strategies were independent of both their level of job satisfaction and the climate of the school in which they were teaching, arguably increasing confidence in the use of consensus-based judgement to identify strategies that are generally better or worse than others. That said, it should be noted that the teachers in this sample scored relatively high on both of these variables, and this restricted range limits the extent to which these particular findings can be generalised. 


\section{Conclusions, Limitations and Future Directions}

This study set out to explore the interpersonal dimension of teaching in the Irish postprimary context. Drawing on seven underlying problem-solving strategies outlined by Stemler et al. (2006) as a conceptual framework, and a sample of post-primary teachers in Ireland as knowledgeable consultants, the consensus-based judgement approach was employed to identify what it might mean to be skilled in the interpersonal dimension of teaching. The overarching aim was to provide a potentially helpful reference point for ITE programme providers seeking to develop their students' skills in this dimension.

Overall, the findings suggest that the confer strategy is generally regarded as a suitable way of dealing with many challenging social situations encountered in the postprimary teaching profession in Ireland. That is, the teachers in this study tended to agree that regardless of whether a 'challenge' originates from a student, a parent or a colleague, it is often appropriate for a teacher to engage the individual concerned in a rational discussion, and explain their point of view on the matter. Similarly, the option of consulting with a colleague as to the best course of action is also regarded as an advisable option in many circumstances. On the other hand, it seems that strategies such as avoid and delegate, each of which represent a certain reluctance to engage with a problem (either by ignoring it completely or passing it on to someone else), are typically regarded as unsuitable strategies for dealing with such situations. These preferences held true regardless of various individual and contextual factors.

Based on these findings, it is suggested that PSTs should be encouraged to appreciate the distinction between these types of strategies. Indeed, it may be helpful for students to engage in role-play situations with their peers and lecturers based on scenarios similar to those depicted in the TKI-HS during initial teacher education 
programmes. This may facilitate the development of the skills needed to engage in strategies such as confer, and help them to realise the benefits of consultation with experienced others. Such an activity may also provide opportunities for them to discuss why, as the data in this study indicate, certain strategies may be more or less appropriate in certain situations. Engagement in these role-plays may be especially timely in the weeks leading up to school placement.

Limitations of this study are acknowledged, such as the small sample size and non-random sampling procedure. Future research employing a larger and more diverse sample would be welcomed, however, these findings nonetheless provide a baseline for understanding and thinking about the interpersonal dimension of teaching in Irish postprimary schools. Not only could this be shared with ITE programme providers as outlined above, more comprehensive empirical data could also inform the development of a formal assessment of interpersonal skills in teaching, specific to the Irish context. Indeed, although the TKI-HS has previously been used as an assessment instrument to make inferences about individual teachers' levels of interpersonal skills (e.g., Grigorenko et al., 2006), it should be appreciated that in order to do so, a series of judgements first needs to be made regarding the 'correctness' of the various response options, and these judgements have been shown to vary across different cultures (Stemler et al., 2018). In other words, before embarking on the process of attempting to measure teachers' interpersonal skills in a particular cultural context, it is necessary to first identify what the construct might 'look like' in that context - which is precisely what this study set out to achieve.

The challenges inherent in defining and understanding the interpersonal dimension of teaching with a view to attempting to measure it are, as mentioned previously, not specific to this particular construct. Rather, they reflect a common theme 
in the broader literature concerning the assessment of complex skills and procedural types of knowledge. Demand for these types of assessments is growing (Adamson \& Darling-Hammond, 2015), and the TKI-HS can in fact be classified as a 'situational judgement test' (SJT) - an assessment format regarded by many as a potentially effective means of gathering information about non-cognitive constructs (McDaniel \& Nguyen, 2001). Aside from interpersonal skills, other areas commonly targeted by SJTs include leadership, personality composites and teamwork skills (Christian, Edwards \& Bradley, 2010), and the issue of how to identify what constitutes a 'correct' vs. an 'incorrect' response to items attempting to measure such constructs has been subject to debate in the SJT literature (Bergman et al., 2006). Consensus-based judgement is regarded as an acceptable technique and consequently is frequently used, however, an additional complication is that once correct/incorrect responses have been identified, there are subsequent decisions to be made regarding how precisely to use this information to assign scores to individual responses. Indeed, previous studies using the $T K I-H S$ as an assessment instrument have implemented various different scoring methods (e.g. Grigorenko et al. 2006 vs Elliott et al., 2011).

A detailed discussion of the issues that need to be taken into account when attempting to develop a scoring approach for an SJT is beyond the scope of this paper. However, it is suggested that future research could compare various approaches to scoring the TKI-HS using data collected in this study as a reference point. Should a suitable scoring system be identified, the TKI-HS could potentially be used in Ireland to provide a measure of individual teachers' (or prospective teachers') interpersonal skills, for example, before and after engaging in CPD, or before and after school placement as part of initial teacher education. In addition, the findings of such research may provide 
insights relevant to the assessment of complex, non-cognitive skills and ' $21^{\text {st }}$ century' competencies more generally. 


\section{References}

Adamson, F. \& Darling-Hammond, L. (2015). Policy pathways for twenty-first century skills. In P. Griffin \& E. Care (Eds.) Assessment and teaching of $21^{\text {st }}$ century skills: Methods and approach (pp. 293-310). Netherlands: Springer Science and Business Media.

Bergman, M.E., Drasgow, F., Donovan, M.A., Henning, J.B., \& Juraska, S.E., (2006). Scoring Situational Judgement Tests: Once you get the data, your troubles begin. International Journal of Selection and Assessment, 14 (3), 223-235.

Brackett, M.A., Palomera, R., Mojsa, J., Reyes, M. \& Salovey, P. (2010). Emotion regulation ability, job satisfaction and burnout among British secondary school teachers. Psychology in the Schools, 4, 406-417.

Bronfenbrenner, U. (1979). The ecology of human development: Experiments by nature and design. Cambridge: Harvard University Press.

Bronfenbrenner, U. (2005). Making human beings human: Bioecological perspectives on human development. Thousand Oaks, CA: Sage.

Christian, M.S. Edwards, B.D. \& Bradley, J.C. Situational Judgement Tests: Constructs assessed and a meta-analysis of their criterion-related validities. Personnel Psychology, 63 (1)

Conway, P.F. \& Murphy, R. (2013). A rising tide meets a perfect storm: New accountabilities in teaching and teacher education in Ireland. Irish Educational Studies, 32 (1), 11-36.

Devine, D. Fahie, D. \& McGillicuddy, D. (2013). What is 'good' teaching? Teacher beliefs and practices about their teaching. Irish Educational Studies, 32 (1), 83108. 
Darling-Hammond, L. (2000). Teacher Quality and Student Achievement. Educational Policy Analysis Archives, 8 (1). Available online: https://epaa.asu.edu/ojs/article/ viewFile/392/515

Darmody, M \& Smyth, E. (2016). Entry to Programmes of Initial Teacher Education. Dublin: ESRI/The Teaching Council.

Department of Education \& Skills (2015). Framework for Junior Cycle 2015.

Eaude, T. (2015). What makes primary class teachers special? Exploring the features of expertise in the primary classroom. Teachers and Teaching, 20 (1), 40-48

Elliott, J.G., Stemler, S.E., Sternberg, R.J., Grigorenko, E.L., \& Hoffman, N. (2011). The socially skilled teacher and the development of tacit knowledge. British Educational Research Journal, 37 (1), 83-103

Grigorenko, E., Sternberg, R. \& Strauss, S. (2006). Practical intelligence and elementary-school teacher effectiveness in the United States and Israel: Measuring the predictive power of tacit knowledge. Thinking Skills and Creativity, 1, 14-33.

Guerriero, S. (Ed.) (2017). Pedagogical Knowledge and the Changing Nature of the Teaching Profession. OECD Publishing: Paris.

Gutman, L. \& Schoon, I. (2016). A synthesis of causal evidence linking non-cognitive skills to later outcomes for children and adolescents. In: M.S. Khine \& S. Areepattamannil (Eds.), pp. 171-198. Non-Cognitive Skills and Factors in Educational Attainment.

Heckman, J. \& Rubinstein, Y. (2001). The Importance of Noncognitive Skills: Lessons from the GED Testing Program. American Economic Review, 91 (2), 145-149

IEA (2014). TIMSS 2015 Teacher Questionnaire @. TIMSS \& PIRLS International Study Centre, Lynch School of Education, Boston College. 
Ingersoll, R.M. (2003). Is there really a teacher shortage? University of Washington: Center for the Study of Teaching and Policy.

Jennings, P.A \& Greenberg, M.T. (2009). The prosocial classroom: Teacher social and emotional competence in relation to student and classroom outcomes. Review of Educational Research, 79, 491-525.

Jones, S.M., Bouffard, S.M., \& Weissbourd, R. (2013). Educators' social and emotional skills vital to learning. Kappan Magazine 98 (4), 62-65

Klassen, R.M. \& Kim, L.E. (2019). Selecting teachers and prospective teachers: A meta-analysis. Educational Research Review, 26, 32-51.

Legree, P.J., Psotka, J., Tremble, T. \& Bourne, D.R. (2005). Using Consensus Based Measuremnt to Assess Emotional Intelligence. In R. Schulze \& R. Roberts (Eds.), Emotional Intelligence: An International Handbook (pp. 155-178) Cambridge, MA: Hogrefe \& Huber

Looney, J. (2011). Developing High-Quality Teachers: teacher evaluation for improvement. European Journal of Education, 46 (4), 440-455

McDaniel, M.A. \& Nguyen, N.T. (2001). Situational Judgement Tests: A Review of Practice and Constructs Assessed. International Journal of Selection and Assessment, 9 (1/2), 103-113

Mostafa, T. \& Pal, J. (2018). Science teachers' satisfaction: Evidence from the PISA 2015 teacher survey. OECD Education Working Papers No. 168. OECD Publishing: Paris.

OECD (2005). Teachers Matter: Attracting, Developing and Retaining Effective Teachers. OECD Publishing: Paris. 
OECD (2014). PISA 2015 General Teacher Questionnaire. Retrieved from: https://nces.ed.gov/surveys/pisa/questionnaire.asp

Patti, J., Holzer, A.H, Brackett, M.A., \& Stern, R. (2015). Twenty-first century professional development for educators: a coaching approach grounded in emotional intelligence. Coaching: An International Journal of Theory, Research \& Practice, 8 (2), 96-119.

Sahlberg, P. (2010). The Secret to Finland's Success: Educating Teachers. Stanford Center for Opportunity Policy in Education: Research Brief.

Steiner, L. (2010). Using Competency-Based Evaluation to Drive Teacher Excellence: Lessons from Singapore. Building an Opportunity Culture for Amercia's Teachers. Public Impact: North Carolina.

Stemler, S.E., Elliott, J., Grigorenko, E.L., Jarvin, L., \& Sternberg, R.J. (2002). Tacit Knowledge Inventory for High School Teachers.

Stemler, S.E., Elliott, J.G., Grigorenko, E.L. \& Sternberg, R.J. (2006). There's more to teaching than instruction: seven strategies for dealing with the practical side of teaching. Educational Studies, 32 (1), 101-118.

Stemler, S.E., Elliott, J.G., O’Leary, M., Scully, D., Karakolidis, A. \& Pitsia, V. (2018, April). A Cross-Cultural Study of High-School Teachers' Tacit Knowledge of Interpersonal Skills. Paper presented at the Annual Meeting of the American Educational Research Association, New York. Retrieved [20 $0^{\text {th }}$ July 2018] from the AERA Online Paper Repository.

Sternberg, R.J. (1999). The theory of successful intelligence. Review of General Psychology, 3, 292-316.

TCD (2017). Postgraduate Courses. Trinity College: Dublin.

Teaching Council of Ireland (2017). Initial Teacher Education: Criteria and Guidelines for Programme Providers. 
Torff, B. \& Sessions, D.N. (2005). Principal's perceptions of the causes of teacher ineffectiveness. Journal of Educational Psychology, 97 (4), 530-537.

Wagner, R.K. \& Sternberg, R.J. (1985). Practical Intelligence in Real-World Pursuits: The Role of Tacit Knowledge. Journal of Personality and Social Psychology, $49(2), 436-458$.

Zeichner, K. (2012) The Turn Once Again Toward Practice-Based Teacher Education. Journal of Teacher Education, 63 (5), 376-382.

\section{Appendices}

Figure 3 here

Figure 4 here

Figure 5 here

\section{Acknowledgements}

The authors gratefully acknowledge Prof. Steven Stemler (Wesleyan University), for granting them permission to adapt and use the $T K I-H S$ for this research, and for providing sound advice on some methodological aspects of the study. Thanks are also due to Prof. Michael O'Leary, Director of CARPE, for his helpful comments on drafts of the manuscript. The work of CARPE is financially supported by Prometric, a test development, delivery and data management company headquartered in Baltimore, MD. The content of this paper has not been influenced in any way by Prometric, and is solely the responsibility of the authors. 


\section{Tables}

Table 1. Defining characteristics and behaviours associated with each of the seven problem-solving strategies underlying the interpersonal dimension of teaching (adapted from Stemler et al., 2006)

\begin{tabular}{|c|c|}
\hline Strategy & Defining characteristics and behaviours \\
\hline Avoid & $\begin{array}{l}\text { - Teacher avoids, delays or puts off dealing with a situation or } \\
\text { problem } \\
\text { - No action is taken at all, or actions that are taken to not deal } \\
\text { directly with the situation }\end{array}$ \\
\hline Comply & $\begin{array}{l}\text { - Teacher does whatever is asked of him or her, regardless of who } \\
\text { is asking } \\
\text { - Teacher takes action that can be interpreted as actively } \\
\text { condoning behaviours of others in the situation }\end{array}$ \\
\hline Confer & $\begin{array}{l}\text { - Teacher engages in verbal discussion with source of interaction } \\
\text { - Conversation takes place in a private, one-on-one setting and is } \\
\text { characterized by rational explanation of the teacher's point of } \\
\text { view }\end{array}$ \\
\hline Consult & $\begin{array}{l}\text { - Teacher appeals to an external source for advice } \\
\text { - Teacher asks people to work together to solve the problem }\end{array}$ \\
\hline Delegate & $\begin{array}{l}\text { - Teacher either implicitly or explicitly delegates responsibility for } \\
\text { taking action to someone else } \\
\text { - Teacher absolves him/herself of responsibility for action }\end{array}$ \\
\hline Legislate & $\begin{array}{l}\text { Teacher explicates rules governing future actions of self and } \\
\text { others }\end{array}$ \\
\hline Retaliate & $\begin{array}{l}\text { - Teacher reacts physically or verbally in direct response to a } \\
\text { situation } \\
\text { - Direct response is often like-for-like in nature and involves } \\
\text { punishment }\end{array}$ \\
\hline
\end{tabular}


Table 2. Questions used to measure job satisfaction and school climate, and their component items.

\begin{tabular}{|c|c|}
\hline Job Satisfaction* & School Climate** \\
\hline $\begin{array}{l}\text { Please indicate the extent to which you } \\
\text { agree or disagree with each of the } \\
\text { following statements... }\end{array}$ & $\begin{array}{l}\text { Thinking about the school in which you } \\
\text { currently teach, please indicate the extent } \\
\text { to which you agree or disagree with the } \\
\text { following statements... }\end{array}$ \\
\hline $\begin{array}{l}\text { The advantages of being a teacher } \\
\text { clearly outweigh the } \\
\text { disadvantages. }\end{array}$ & $\begin{array}{l}\text { The students behave in an orderly } \\
\text { manner. }\end{array}$ \\
\hline $\begin{array}{l}\text { If I could decide again, I would } \\
\text { still choose to work as a teacher. }\end{array}$ & $\begin{array}{l}\text { The students are respectful of the } \\
\text { teachers. }\end{array}$ \\
\hline $\begin{array}{l}\text { I regret that I decided to become a } \\
\text { teacher. }\end{array}$ & $\begin{array}{l}\text { The students respect school } \\
\text { property. }\end{array}$ \\
\hline I enjoy working at this school. & $\begin{array}{l}\text { The school has clear rules about } \\
\text { student conduct. }\end{array}$ \\
\hline $\begin{array}{l}\text { I would recommend my school as } \\
\text { a good place to work. }\end{array}$ & $\begin{array}{l}\text { The school's rules are enforced in } \\
\text { a fair and consistent manner. }\end{array}$ \\
\hline $\begin{array}{l}\text { I wonder whether it would have } \\
\text { been better to choose another } \\
\text { profession. }\end{array}$ & $\begin{array}{l}\text { Parents are supportive of school } \\
\text { activities. }\end{array}$ \\
\hline $\begin{array}{l}\text { I am satisfied with my } \\
\text { performance in this school. }\end{array}$ & $\begin{array}{l}\text { Parents are committed to ensure } \\
\text { that students are ready to learn. }\end{array}$ \\
\hline $\begin{array}{l}\text { All in all, I am satisfied with my } \\
\text { job. }\end{array}$ & $\begin{array}{l}\text { Parents have high expectations } \\
\text { regarding student achievement. }\end{array}$ \\
\hline
\end{tabular}


Table 3. Respondent characteristics

\begin{tabular}{lrlrrr}
\hline Gender & $\%$ & Level of education: & $\%$ & Years of & $\%$ \\
Female & 71.0 & Bachelor's & 42.0 & experience: & 1.4 \\
Male & 29.0 & Master's & 52.2 & $0-1$ & 18.8 \\
& & Doctorate & 5.8 & $2-4$ & 24.6 \\
& & $5-9$ & 15.9 \\
& & & $10-14$ & 10.1 \\
& & & $15-19$ & 8.7 \\
& & & $20-24$ & 11.6 \\
Main subject & & & $25-29$ & \\
area: & & & $30+$ & \\
$\quad$ Applied & 7.2 & in: & & \\
Sciences & 13.0 & 1 & & \\
$\quad$ Business & 30.4 & 2 & 26.1 & \\
Studies & 29.0 & 3 & 23.2 & \\
$\quad$ Languages & 11.6 & $>4$ & 39.1 & \\
$\quad$ Sciences & 8.8 & & & \\
$\quad$ Social Studies & & &
\end{tabular}

Table 4. Descriptive statistics for job satisfaction and school climate

\begin{tabular}{lrrrr}
\hline & $\boldsymbol{M}$ & $\boldsymbol{S D}$ & Min & Max \\
\hline Job Satisfaction & 26.18 & 4.052 & 17 & 32 \\
\hline School Climate & 23.35 & 4.712 & 13 & 32 \\
\hline
\end{tabular}


Table 5. Mean ratings for each strategy by scenario

\begin{tabular}{|c|c|c|c|c|c|c|c|}
\hline Strategy & Avoid & Comply & Confer & Consult & Delegate & Legislate & Retaliate \\
\hline $\begin{array}{c}\text { Scenario } \\
1\end{array}$ & 2.86 & 1.19 & 6.3 & 2.48 & 2.42 & 4.28 & 1.83 \\
\hline $\begin{array}{c}\text { Scenario } \\
2 \\
\end{array}$ & 4.55 & 5.33 & 4.82 & 5.31 & 3.66 & 5.86 & 3.72 \\
\hline \begin{tabular}{c|} 
Scenario \\
3 \\
\end{tabular} & 4.72 & 2.18 & 6.34 & 5.3 & 3.08 & 3.3 & 1.54 \\
\hline $\begin{array}{c}\text { Scenario } \\
4\end{array}$ & 1.24 & 5.6 & 5.6 & 5.81 & 3.43 & 3.6 & 3.97 \\
\hline $\begin{array}{c}\text { Scenario } \\
5\end{array}$ & 1.87 & 6.25 & 6.16 & 5.93 & 2.35 & 6.02 & 4.09 \\
\hline $\begin{array}{c}\text { Scenario } \\
6\end{array}$ & 4.11 & 3.87 & 4.84 & 5.65 & 2.15 & 3.87 & 1.35 \\
\hline $\begin{array}{c}\text { Scenario } \\
7\end{array}$ & 3.2 & 3.25 & 4.31 & 6.29 & 2.8 & 2.53 & 2.49 \\
\hline $\begin{array}{c}\text { Scenario } \\
8 \\
\end{array}$ & 2.87 & 4.51 & 5.2 & 3.75 & 2.82 & 4.28 & 3.63 \\
\hline $\begin{array}{c}\text { Scenario } \\
9\end{array}$ & 1.72 & 1.28 & 5.06 & 4.83 & 4.46 & 2.63 & 4.78 \\
\hline $\begin{array}{c}\text { Scenario } \\
10\end{array}$ & 4.19 & 3.8 & 5.7 & 3.44 & 3.46 & 5.28 & 4.45 \\
\hline $\begin{array}{c}\text { Scenario } \\
11\end{array}$ & 4.8 & 1.69 & 4.3 & 6.65 & 2.38 & 4.67 & 4.28 \\
\hline
\end{tabular}

$\ldots \ldots \ldots \ldots \ldots \ldots$

= 'worst' response 
Susan, a girl in Ms. Wilson's third year Spanish class, tends to perform below average on oral exercises and class tests. However, she did much better on a recent project. The difference is so pronounced that Ms. Wilson thinks that maybe it was not Susan's work. She knows that Susan's father is a fluent Spanish speaker, and could have helped her with the project. Ms. Wilson asks Susan whether the project is her work, and she affirms that it is. Susan's father calls Ms. Wilson the next day to tell her that he is upset that Ms. Wilson could even suspect his daughter would cheat. What should Ms. Wilson do?

\section{Given the situation, please rate the extent to which you agree or disagree} with each of the following statements.

1 2 3

$$
4
$$

5

6 7

\section{Strongly Disagree}

Neutral

\section{Strongly Agree}

1. [COMPLY] Ms. Wilson should tell Susan's father that she understands his concerns and is reassured now that they've had an opportunity to talk things through.

2. [CONSULT] Ms. Wilson should ask Susan's other teachers and guidance counsellor about Susan's performance on structured tests as compared with open-ended projects.

3. [CONFER] Ms. Wilson should explain why she became suspicious about Susan's work, mentioning her low test scores.

4. [AVOID] Ms. Wilson should tell Susan's father that she is on her way to a meeting and will call him back (with no intention of doing so)

5. [DELEGATE] Ms. Wilson should tell Susan's father that she can put him in touch with the vice principal, who can field his concerns.

6. [LEGISLATE] Ms. Wilson should inform Susan's father that she has a personal policy of following up on anyone she suspects of cheating.

7. [RETALIATE] Ms. Wilson should explain to Susan's father that she understands that he wants to help his daughter succeed, but that doing her work for her will only hurt her in the long run.

Figure 1. Example Scenario and Response Options (adapted from the TKI-HS, Stemler et al., 2002). 


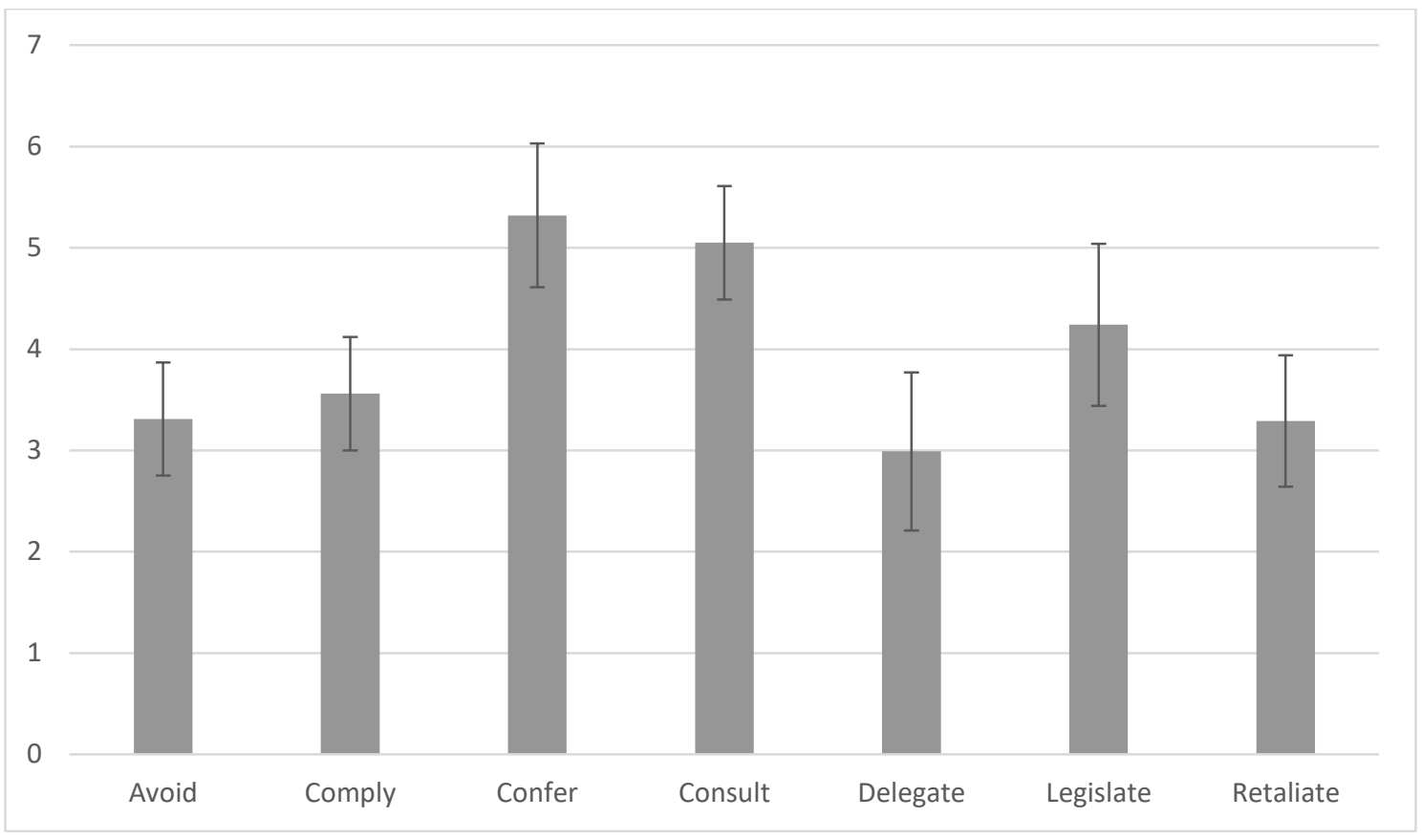

Figure 2. Teachers' mean ratings of each problem-solving strategy across all situations.

Note: error bars represent standard deviations of ratings. 


\section{Scenario 1}

Ms. Johnson's relationship with the students in her Transition Year English class this year is good. They like her lessons, they are motivated and work hard, and the atmosphere is conducive to learning. One day, Robert, a friendly but neither excellent nor hard working student, asks Ms. Johnson to have coffee with him at a nearby coffee shop after school. What should Ms. Johnson do?

\section{Given the situation, please rate the extent to which you agree or disagree} with each of the following statements.

$\begin{array}{lcccccc}1 & 2 & 3 & 4 & 5 & 6 & 7 \\ \text { Strongly Disagree } & & \text { Neutral } & & & \text { Strongly Agree }\end{array}$

1. [COMPLY] Ms. Johnson should go with Robert to have coffee.

2. [CONSULT] Ms. Johnson should tell Robert that she will consult the policy on meeting with students outside of school, and then ask other teacher what they would do in a similar situation.

3. [LEGISLATE] Ms. Johnson should decide to institute a strict policy about meeting with students outside of class, and inform Robert.

4. [DELEGATE] Ms. Johnson should tell Robert that she will have to check with the principal to see if it is okay for a teacher to have coffee with the student.

5. [CONFER] Ms. Johnson should tell Robert that this would not be appropriate, because she is his teacher.

6. [AVOID] Ms. Johnson should deflect the issue by changing the topic of conversation.

7. [RETALIATE] Ms. Johnson should say “Sure, why don't we grab a beer while we're at it. I can't go out for coffee with a student!"

Figure 3. Scenario 1 (adapted from the TKI-HS, Stemler et al., 2002). 


\section{Scenario 5}

Mr. Moore has a third year class. For the most part, the students in the class are interested in the topics and listen to what he has to say. Some of them understand new topics easily, while others have difficulties understanding basic concepts and ask questions that show they don't understand the content. William, one of the brighter students, is obviously bored with the pace of the class, so he has begun to laugh and make fun of students who ask questions. What should Mr. Moore do?

Given the situation, please rate the extent to which you agree or disagree with each of the following statements.

23

4

5

6 7

Strongly Disagree

Neutral Strongly Agree

1. [RETALIATE] Mr. Moore should tell William, in front of the class, that any further disruption will be punished.

2. [AVOID] Mr. Moore should ignore William's inappropriate behaviour.

3. [CONSULT] Mr. Moore should speak with William's other teachers to see if he is above average in other subjects, and if this has led to disruptive behaviour.

4. [LEGISLATE] Mr. Moore should go over his rules with the class, emphasizing the importance of respect.

5. [COMPLY] Mr. Moore should talk to William in private, tell him that he recognizes how bright he is, and that he will find assignments that will really challenge him.

6. [CONFER] Mr. Moore should speak to William privately about his rudeness in class.

7. [DELEGATE] Mr. Moore should send William to the principal.

Figure 4. Scenario 5 (adapted from the TKI-HS, Stemler et al., 2002). 


\section{Scenario 10}

Ms. Young is a teacher who loves her job; she likes the students and they like her. She does a lot of extra work outside the classroom, like preparing projects and attending extra curricular activities. Her family and friends keep telling her that she does not make enough time for them. She realizes that she spends most of her time with activities related to school, so she makes plans to go out for a lunch with her family in a nice restaurant one Saturday afternoon. The whole family are really looking forward to it. That week, however, one of her best students, David, who is on the school football team, tells her that he is looking forward to seeing her at the cup final, which is also taking place on Saturday. Before she can get a word in, he continues, saying "I think you must be our good luck charm. We've never lost a game when you've been there!" What should Ms. Young do?

\section{Given the situation, please rate the extent to which you agree or disagree} with each of the following statements.

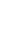

4 5 6 Strongly Disagree Neutral Strongly Agree

1. [RETALIATE] Ms. Young should tell David that she can't come to the game, but that there is no such thing as a good luck charm.

2. [AVOID] Ms. Young should smile warmly without committing herself, and then go out for lunch with her family.

3. [LEGISLATE] Ms. Young should make it a personal policy that she will not break any more commitments with her family for a school activity.

4. [COMPLY] Ms. Young should take her family to the game and go out for lunch afterwards.

5. [CONSULT] Ms. Young should sit down with her family, and make a decision together about what to do.

6. [DELEGATE] Ms. Young should tell David that she will have to ask her family first because she already made plans with them.

7. [CONFER] Ms. Young should explain to David that she has made a prior commitment.

Figure 5. Scenario 10 (adapted from the TKI-HS, Stemler et al., 2002). 
